\title{
Verification of Properties of Concrete Reinforcement Bars: Nigeria as Case Study
}

\author{
Arum, C
}

\begin{abstract}
An investigation was conducted into the level of conformance of ribbed steel bars used in Nigeria's structural concrete practice to relevant international and local provisions. In this research, all bars imported into Nigeria from member countries of ISO as well as bars marked with the identity of the local producing mill are classified as steel of recognizable origin. On the other hand, bars imported from ISO non-member countries as well as those without identifying mark of the producing works are classified as steel of non-recognizable origin. The results of the investigation showed that steel of recognizable origin satisfy both local and ISO requirements for strength and ductility. On the other hand, steel of non-recognizable origin failed to satisfy the above requirements for high-yield ribbed bars but satisfies the local specifications if used as mild steel.
\end{abstract}

Keywords: Ribbed steel bar, Strength, Ductility, Recognizable, Tensile test

\section{Introduction}

A structure is usually designed to ensure that it does not fail prematurely, whether it is collapse or service failure. Unfortunately, cases of premature structural failure abound. In Nigeria, reported cases of structural failure have recently become frequent, especially for buildings. Several researchers have investigated into the causes of building collapse. One of the most frequently adduced causes is the non-conformance of structural properties of materials used in the actual construction to the properties of materials specified for it. The works of Daodu and Raji (2005) are instructive in this respect. 
In Nigeria, the steel reinforcement bar need for structural concrete is partly produced by the country's inland rolling mills while the balance is sourced through import. The importation is carried out mostly by private entrepreneurs and the quality of such imported product is not always guaranteed. Regarding the structural properties of steel for the reinforcement of concrete, the design practice in Nigeria adapts the specifications of British Standards, with due consideration to the information on bar properties as provided by the local steel bar producing rolling mills. Based on the information by the local mills, high-yield ribbed bars have minimum guaranteed yield (or proof) stress of $420 \mathrm{~N} / \mathrm{mm}^{2}$, tensile strength of $500 \mathrm{~N} / \mathrm{mm}^{2}$ and percentage elongation of $10 \%$. Accordingly $420 \mathrm{~N} / \mathrm{mm}^{2}$ is generally used in design as the characteristic value for the yield strength of high-yield ribbed bars.

Since the reinforcement steel used in Nigeria is neither always of British origin nor necessarily produced by the country's rolling mills, differences are bound to arise in the strengths of steel assumed in design and those used for actual construction, unless tests are carried out on every batch of imported steel delivered on construction site. This is because Nigeria's construction practice shows that most steel bars delivered on a given site are produced by different manufacturers, often without adequate and reliable information regarding their structural properties. For steel exporters that are members of International Organization for Standardization (ISO), their products are usually marked in a recognizable manner and the identity of the manufacturer countries are marked in a recognizable form on each length of bar. However, bar merchants import steel not only from ISO member countries but also from non-member countries and in many cases steel sold in the local bar market does not contain information about their strengths and the manufacturer countries.

Although the separate batches of steel bars supplied by the local rolling mills may contain information about the producing mills as well as the product structural properties, such information are not available as markings on the bodies of individual bars. In addition, a 
large number of construction sites do not obtain their supplies directly from the producing mills but purchase them as groups of single bars from the open market. The result is that some steel bars are deposited at the construction sites without any reliable information about their structural quality and their producing mills. Consequently, it is difficult to visually differentiate locally produced bars from those imported from ISO non-member countries.

Owing to the foregoing, in this investigation, reinforcement bars sourced from the local bar market are classified as steel of recognizable origin if they are marked in accordance with the provisions of International Organization for Standardization, for imported bars, or they have marks identifying the producing local rolling mill, for locally produced bars. On the other hand, if the bars are not marked according to International Standards, or are not marked at all, they are referred to as steel of non-recognizable origin. The implication is that all bars whether imported or locally produced but without clear marks indicating their source, are for the purpose of this research, grouped as steel of non-recognizable origin. The research will concern itself only with ribbed bars as the most widely used reinforcement bars for concrete. The required characteristic values for the strengths and ductility parameters of these steel grades as given by ISO 6935-2 is reproduced here as Table1. According to this code, there are two multinational systems for identification of ribbed bars. One is the system according to EURONORM 80-85 while the other is system according to ASTM A 615 M-88. The country of origin marking according to EURONORM 80-85 system is shown in Table 2 and the actual marking on the surface of the bars is illustrated in Figs. 1 and 2. The ASTM A 615 M-88 system of marking is illustrated in Fig.3.

In view of the above background, the aim of this investigation is to verify the characteristic strength and ductility parameters of ribbed reinforcement bars in the Nigeria bar market with a view to determining the extent to which they conform to the requirements of International Organization for Standardization and hence, to determine 
whether or not they contribute to the incidence of building failures in the country. Accordingly, the specific objectives of the research are to:

- obtain test samples of various diameters of ribbed bars of recognizable and non-recognizable origin from the open market and subject them to tensile test;

- analyze the strength and ductility properties obtained from the tensile test and verify the extent of their conformance with the specifications of ISO;

- compare the results of the tensile test analyses for bars of recognizable and those of non-recognizable origin, and

- offer recommendations on the use of reinforcement bars purchased from the open market for structural concrete.

\section{Materials and Method}

Test specimens were obtained from ribbed bars of circular cross section of nominal diameters $10,12,16,20$, and $25 \mathrm{~mm}$, representing the most widely used bar sizes for the local concrete reinforcement needs. Fifteen (15) test pieces were prepared from each nominal bar diameter in accordance with the recommendations of International Organization for Standardization Accordingly, for each diameter, the gauge length was made 5 times the diameter. The gauge length was marked on each sample with the aid of ruler, scriber, hammer and center punch prior to testing. The test pieces were cut off from full $12 \mathrm{~m}$ lengths of ribbed bars sampled randomly from the local bar markets at Lagos, Ibadan, Akure and Ife towns. The steel bars available in these towns represent the general situation in the bar market throughout the country.

According to ISO (1998) for the purpose of testing, a delivery should be subdivided into test units with a maximum mass of 50 tonnes or a fraction thereof. Also, each test unit should consist of products of the same steel grade and the same nominal diameter from the same cast. In this investigation, it was not possible to establish which products were of same grade and cast. Owing to this difficulty, Ibadan, Akure, 
and Ife markets represented one test unit each while Lagos bar markets were grouped into two test units. Thirty (30) test pieces were sampled from the Lagos test units, fifteen (15) pieces for each of 12 and $16 \mathrm{~mm}$ bar sizes. Fifteen (15) test pieces were sampled from each of Ife, Ibadan, and Akure test units, respectively for bar sizes of 10, 20 and $25 \mathrm{~mm}$. A ruler and vernier calipers were used to measure the dimensions of the test pieces.

The tensile test was carried out in accordance with the recommendations of ISO (1991). The test was conducted at the Materials Testing Laboratory of the Polytechnic Ibadan, using a Universal Testing Machine "Avery-Denison". Owing to the fact that diameters less than $25 \mathrm{~mm}$ could not be tightly gripped by the gripping ends of the machine, smaller diameters were specially prepared by welding attachments to their heads. This was done at adequate distances away from the gauge lengths to ensure that the welds do not introduce stress concentrations within the region of the gauge lengths. Some specimens with the welded attachments are shown in Plate 1 (Before testing) and in Plate 2 (After testing).

At the initial stage of loading the resulting small extensions corresponding to load increments were measured by means of an extensometer attached to the gauge length of the specimen. When the extensions became relatively large, the extensometer was removed. Thereafter dividers, vernier calipers and a ruler were used to measure increments in the gauge length for the purpose of computation of the strains. Given the usual assumption that for a gauge length $L_{0}$ of the specimen, the stress is uniformly distributed for all points on each cross section and for all cross sections perpendicular to the line of action of the load, the tensile stress was computed according to the formula:

$$
\sigma_{t}=\frac{P}{A_{0}}
$$


where $\sigma_{t}=$ tensile stress;

$$
\begin{aligned}
& P=\text { applied load; } \\
& A_{0}=\text { initial cross sectional area of the sample. }
\end{aligned}
$$

Since this uniform stress is assumed to produce a uniform elongation $\Delta L$, the value of the elongation per unit length (or strain) for every increment in load was computed according to the formula:

$$
\varepsilon=\frac{\Delta L}{L_{0}}
$$

where $\varepsilon=$ strain;

$$
\begin{aligned}
& \Delta L=\text { elongation; } \\
& L_{0}=\text { original gauge length. }
\end{aligned}
$$

With the values of stress $(\sigma)$ and strain $(\varepsilon)$ obtained using expressions (1) and (2), a representative stress-strain curve for each bar diameter was drawn. The values of stresses and strains used for the determination of yield stresses were computed from the arithmetic means of the values of loads and extensions for 15 test samples for each bar diameter tested. The high-yield bars tested did not show a clearly marked yield point; consequently, their $0.2 \%$ proof stresses were determined.

The percentage elongation corresponding to fracture (or ductility) was computed according to the following formula:

$$
D_{e}=\frac{L_{f}-L_{0}}{L_{0}} \times 100
$$




$$
\text { or } \quad D_{e}=\varepsilon_{f} \times 100
$$

where $D_{e}=$ percentage elongation (or ductility);

$L_{0}=$ original gauge length;

$L_{f}=$ length of specimen at fracture;

$\varepsilon_{f}=$ unit strain at fracture.

The tensile strength for each specimen was computed as the ratio of the maximum load to the original cross sectional area of the specimen. The characteristic value of the tensile strength for each bar diameter was evaluated in accordance with ISO 6935-2 provisions. Accordingly, to obtain their characteristic values, the following parameters were determined:

a) all individual values, $x_{i}$, of the 15 test pieces $(n=15)$;

b) the mean value, $m_{15}$ (for $\left.n=15\right)$;

c) the standard deviation, $s_{15}$ (for $\left.n=15\right)$.

Each test unit was considered to correspond to the requirements if for all properties the following condition was fulfilled:

$$
m_{15}-2.33 s_{15} \geq f_{k}
$$

where $f_{k}=$ the required characteristic value;

$2.33=$ the value for the acceptability index, $k$, for $n=15$ for a failure rate of $5 \%$.

\section{Results and Discussion}

The tensile test results necessary for the computation of the characteristic values of the tensile strength, as well as the ductility 
properties are shown in Tables 3 to 7 respectively for nominal bar diameters 10, 12, 16, 20 and $25 \mathrm{~mm}$. These tables include test results for both steel of non-recognizable origin (designated "a") and steel of recognizable origin (designated "b").

For steel of non-recognizable origin of bar diameters 12, 20 and $25 \mathrm{~mm}$, the characteristic values of the tensile strength as computed from the test results are lower than the minimum value usually guaranteed by Nigeria's inland rolling mills and used in the local design practice. On the other hand, for steel of recognizable origin, the test values of the characteristic tensile strength satisfy the specified minimum value for all bar diameters tested. For both categories of steel, the values of the standard deviation and the coefficient of variation indicate better uniformity in quality for nominal bar diameters 10 and $12 \mathrm{~mm}$ than the other bar diameters.

Furthermore, for steel of non-recognizable origin none of the bar diameters satisfied the requirement for proof stress, whereas the same requirement was satisfied for all bar diameters for steel of recognizable origin. For percentage elongation, although the locally specified minimum requirement of $10 \%$ was satisfied by all bar sizes for the two categories of steel considered, the test values obtained for steel of non-recognizable origin are much higher than those of their corresponding bar diameters for steel of recognizable origin. In fact whereas none of the percentage elongation values for steel of recognizable origin is close to the minimum value of $26 \%$ specified for plain round bars, the corresponding values for steel of nonrecognizable origin are sufficiently close (for practical purposes) to the $26 \%$ value, with the $25 \mathrm{~mm}$ diameter bars actually meeting the requirement with $29 \%$ elongation. This fact of relatively high percentage elongation, together with the fact of low tensile strength and yield stress, is an indication that although the bars of nonrecognizable origin are ribbed to suggest that they are high-yield steel, they may in fact be mild steel. 
A holistic evaluation of the figures obtained for the tensile strength, proof stress and percentage elongation, as well as the stress-strain diagrams, shows that although all steel tested were ribbed as highyield steel, the strength and ductility properties of steel of nonrecognizable origin agree more with specified requirements for plain round bars than for high-yield ribbed bars. The implication of this fact is that the use of steel of non-recognizable origin for the design and construction of reinforced concrete structures on the assumption that they are high yield steel just because they are ribbed, could cause failure. On the other hand, the above properties as obtained for steel of recognizable origin fully satisfy the requirements for high-yield ribbed bars.

By comparing the minimum yield stress (or $0.2 \%$ proof stress), the minimum tensile strength, the minimum percentage elongation as specified by ISO 6935-2 (see Table 1) and the actual test values as shown in Table 8, it can be concluded that all bar diameters for steel of non-recognizable origin satisfy the relevant requirements for steel grade RB 300, except diameters 12 and $25 \mathrm{~mm}$ whose proof stresses of 275 and $280 \mathrm{~N} / \mathrm{mm}^{2}$ respectively fell short of the specified $300 \mathrm{~N} / \mathrm{mm}^{2}$ by 8.3 and $6.7 \%$. On the other hand, for all tested bar diameters, steel of recognizable origin satisfy the requirements of International Standards for steel grade RB 400 (or RB 400W).

The results of the investigation also revealed very high ratios of the tensile strengths to the proof stresses, especially for bars of nonrecognizable origin and for bar diameters 16,20 and $25 \mathrm{~m}$ of steel of recognizable origin. The import of this is that plastic properties of steel can be widely exploited for designs utilizing those bars. Finally, the research exposed the fact that for steel of non-recognizable origin, the diameters usually sold and assumed in design as 10,16 and $25 \mathrm{~mm}$ were in fact 9,15 and $24 \mathrm{~mm}$ while those assumed to be $20 \mathrm{~mm}$ were a fairly equal mix of 19 and $20 \mathrm{~mm}$ bars. The implication of this fact is that concrete structures reinforced with the defaulting bars contain less steel area than actually required, which is potentially dangerous. 


\section{Conclusion}

From the results of this study, it can be concluded that steel of recognizable origin, satisfy the requirements for tensile strength, proof stress and percentage elongation, both as specified by the local inland rolling mills (and used in the local design practice) and as specified by International Organization for Standardization, for steel grade RB400 (or RB400W). On the other hand, steel of non-recognizable origin failed to satisfy the above requirements for high-yield ribbed bars but appreciably satisfy the requirements of ISO for steel grade RB 300 and the local specifications for plain round mild steel.

\section{Recommendations}

Steel bars sourced from the open market should not be used for the reinforcement of structural concrete without first subjecting them appropriately to tensile test, especially if individual bars from a given batch or unit are not marked according to the requirements of International Standards and do not have identification marks or product characteristics of any of the country's inland rolling mills. In exceptional circumstances where testing of bars before use is not practicable, all ribbed bars of non-recognizable origin should be used as plain bars with the associated structural properties. In addition, even where the bars are used as plain bars, for the purpose of design calculations the 10, 16, 20 and $25 \mathrm{~mm}$ should be respectively taken as $9,15,19$ and $24 \mathrm{~mm}$ unless actual measurements of the dimensions are carried out. 


\section{References}

Arum C, and Babatola J.O (2006) "Failure of Building Structures, Causes an Preventive Measures". Proceedings of the Technical Session at the Annual Engineering Week of the Nigerian Society of Engineers on the theme: The Prospects and Challenges of Engineering Practice in Nigeria. The Nigerian Society of Engineers, Akure, pp.50-61.

Kaminetsky D (1991) Design and Construction Failure. Lessons from Forensic Investigations. McGraw Hill Inc., New York.

Salau M.A (2005) "Design, Construction and Maintenance Measures for Preventing the Collapse of Reinforced Concrete Structures", A paper presented at a 3-day

National Workshop on the theme: Preventing Incidences of Collapsed Buildings and Structures in Nigeria, Lagos.

Daodu O.F.(2005) "Determination of strength and ductility characteristics of steel reinforcement bars produced in Nigeria" Unpublished Post Graduate Diploma Thesis, Federal University of Technology, Akure.

Raji A.K. (2005) "Determination of strength and ductility characteristics of steel reinforcement bars imported into Nigeria". Unpublished Post Graduate Diploma Thesis, Federal University of Technology, Akure, 2005.

Nwabuokei S.O.(2007) “The Nigerian Steel Industry: Delta Steel Company Experience". A paper presented at the Annual Lecture of the School of Engineering and Engineering Technology, Federal University of Technology, Akure.

BSI (Undated): BS4461 Specification for cold worked steel bars or the reinforcement of concrete, British Standards Institution, London.

BSI (Undated): BS4449 Specification for hot rolled steel bars for the reinforcement of concrete, British Standards Institution, London.

OSRCL (Undated): Marketing Brochure, Facts and Figures on Oshogbo Steel Rolling Company Limited, Adwork Limited, Lagos.

ISO (1991) ISO 6935-2 Steel for the reinforcement of concrete, Part 2: Ribbed bars, International Organization for Standardization, Geneva.

ISO (1998). Metallic materials. Tensile testing at ambient temperature, International Organization for Standardization, Geneva, 1998. 
Table 1: Characteristic Values for Upper Yield Stress, Tensile Strength And Percentage Elongation After Fracture (Iso 6935-2:1991)

\begin{tabular}{|c|c|c|c|}
\hline $\begin{array}{c}\text { Steel } \\
\text { Grade }\end{array}$ & $\begin{array}{l}\text { Upper Yield } \\
\text { Stress } \\
\mathrm{N} / \mathrm{mm}^{2}\end{array}$ & $\begin{array}{c}\text { Tensile Strength } \\
\mathrm{N} / \mathrm{mm}^{2}\end{array}$ & $\begin{array}{c}\text { Elongation } \\
\%\end{array}$ \\
\hline RB 300 & 300 & 330 & 16 \\
\hline $\begin{array}{c}\text { RB 400 } \\
\text { RB 400W }\end{array}$ & 400 & 440 & 14 \\
\hline $\begin{array}{c}\text { RB 500 } \\
\text { RB500W }\end{array}$ & 500 & 550 & 14 \\
\hline
\end{tabular}

Table 2: Marking of Country of Origin for High-Yield Steel Bars (Iso 6935-2:1991)

\begin{tabular}{|l|c|}
\hline \multicolumn{1}{|c|}{ Country } & $\begin{array}{l}\text { Number of normal oblique ribs } \\
\text { between two thickened oblique ribs }\end{array}$ \\
\hline Germany & 1 \\
\hline Belgium, Netherlands, Luxemburg & 2 \\
\hline France & 3 \\
\hline Italy & 4 \\
\hline UK, Ireland & 5 \\
\hline Denmark, Sweden, Finland & 6 \\
\hline Spain, Portugal & 7 \\
\hline Greece, Turkey, Czechoslovakia & 8 \\
\hline
\end{tabular}


Arum, $C$

Fig.1: Euronorm 80-85 Marking For Reinforcing Steel Rb 400

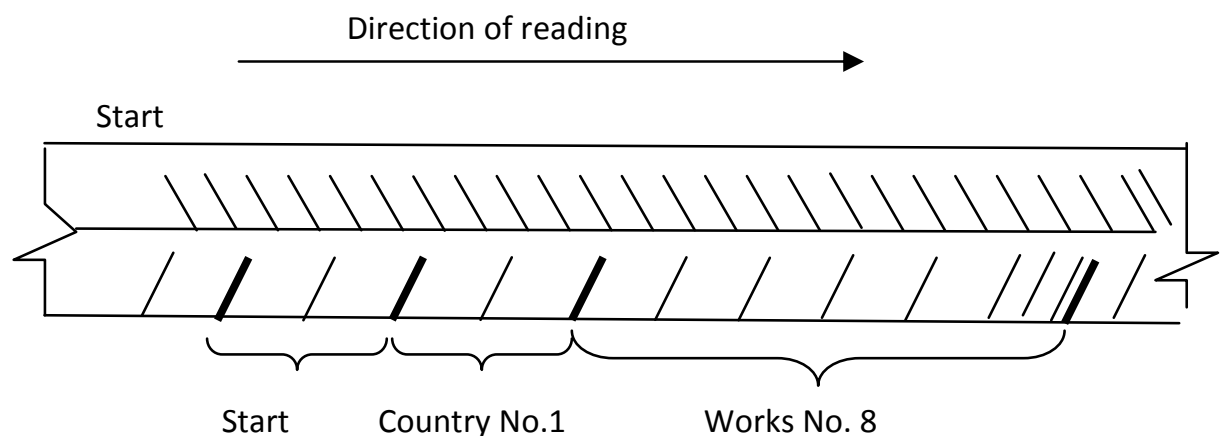

Fig.2: Euronorm 80-85 Marking For Reinforcing Steel Rb 500w

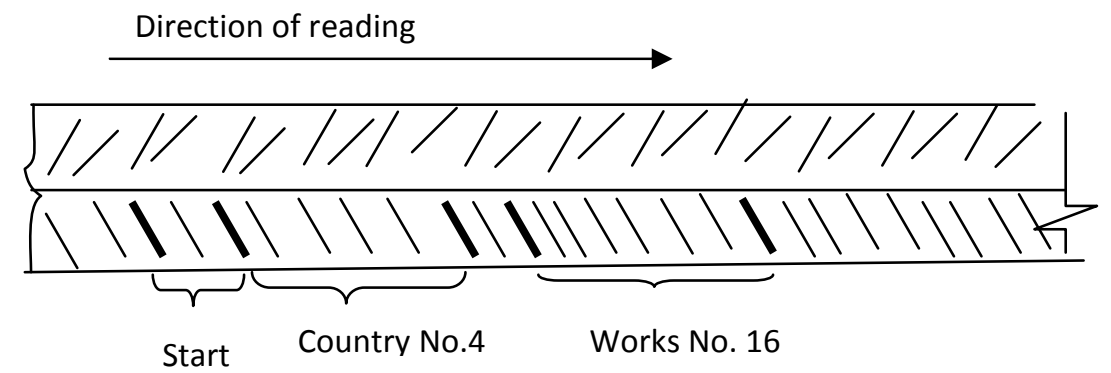

Fig.3: Marking of Steel According to Astm A 615 M-88

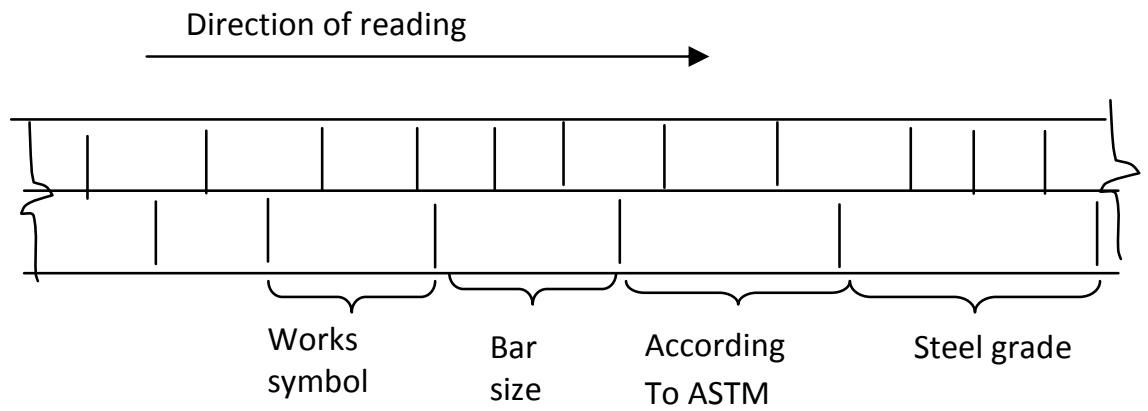


Verification of Properties of Concrete Reinforcement Bars...

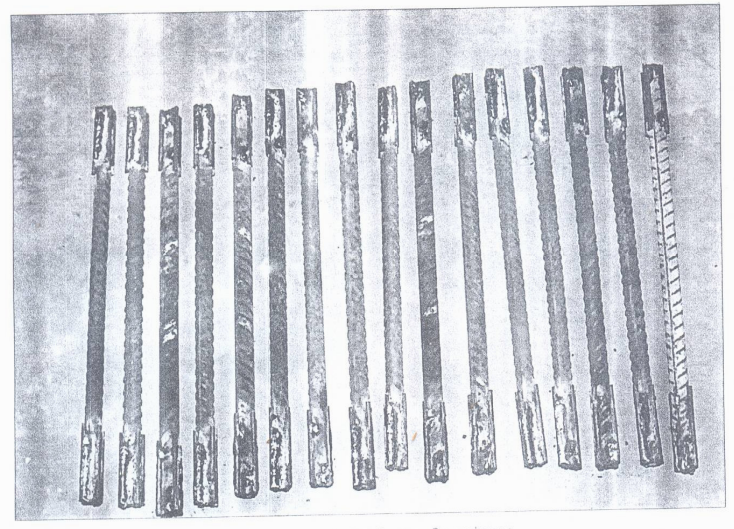

Plate 1: Test Speciment before fracture

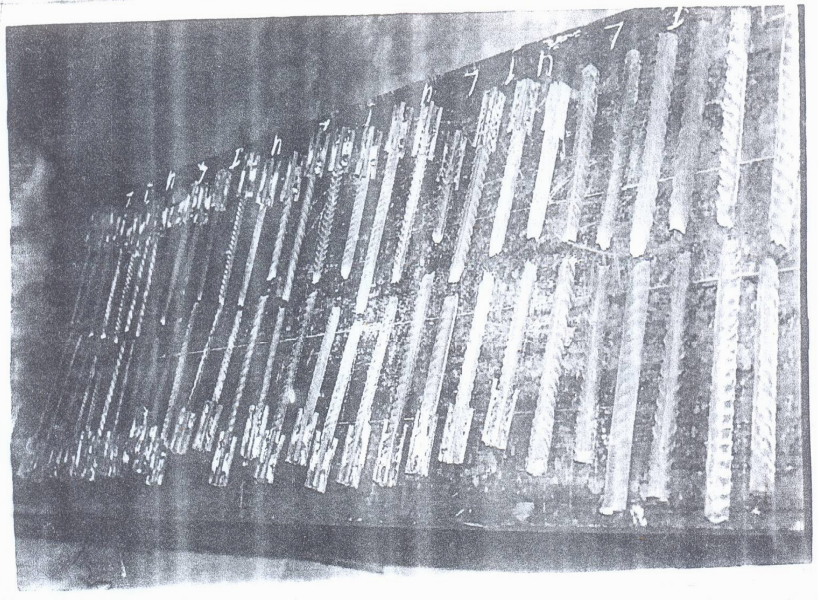

Plate 2: Test Specimens after fracture 
Table 3: Results of the Tensile Test for the Computation of Characteristic Tensile Strength and Mean Percentage Elongation for Steel of Bar Diameter 10mm

\begin{tabular}{|c|c|c|c|c|c|c|c|c|c|}
\hline \multirow[t]{2}{*}{$\mathbf{S} / \mathbf{N}$} & \multicolumn{2}{|c|}{$\begin{array}{l}\text { Maximum } \\
\text { Load }(k \mathbf{N})\end{array}$} & \multicolumn{2}{|c|}{$\begin{array}{l}\text { Tensile Strength } \\
\left(\mathbf{k N} / \mathbf{m m}^{2}\right)\end{array}$} & \multicolumn{2}{|c|}{$\begin{array}{l}\text { Final Length } \\
(\mathrm{mm})\end{array}$} & \multicolumn{2}{|c|}{$\begin{array}{l}\text { Total } \\
\text { Elongation } \\
(\mathbf{m m})\end{array}$} & \multirow{2}{*}{ 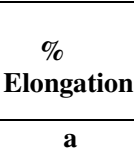 } \\
\hline & $\mathbf{a}$ & b & & & $\mathbf{a}$ & $\mathbf{b}$ & $\mathbf{a}$ & b & \\
\hline 1 & 35.5 & 49.5 & 558 & 630 & 58.0 & 56.0 & 13.0 & 6.0 & 29.0 \\
\hline 2 & 35.5 & 49.5 & 558 & 630 & 58.0 & 59.0 & 13.0 & 9.0 & 29.0 \\
\hline 3 & 37.0 & 50.0 & 582 & 636 & 54.5 & 57.0 & 9.5 & 7.0 & 21.0 \\
\hline 4 & 35.2 & 49.5 & 553 & 630 & 54.0 & 58.0 & 9.0 & 8.0 & 20.0 \\
\hline 5 & 37.1 & 50.0 & 583 & 636 & 56.0 & 56.5 & 11.0 & 6.5 & 24.4 \\
\hline 6 & 35.0 & 48.5 & 550 & 617 & 55.0 & 58.0 & 10.0 & 8.0 & 22.0 \\
\hline 7 & 35.4 & 48.5 & 557 & 617 & 56.0 & 55.5 & 11.0 & 5.5 & 24.4 \\
\hline 8 & 36.0 & 49.0 & 566 & 623 & 50.0 & 56.5 & 5.0 & 6.5 & 11.0 \\
\hline 9 & 35.2 & 49.5 & 553 & 630 & 57.0 & 57.5 & 12.0 & 7.5 & 27.0 \\
\hline 10 & 37.0 & 49.5 & 582 & 630 & 54.0 & 57.0 & 9.0 & 7.0 & 20.0 \\
\hline 11 & 35.5 & 49.0 & 558 & 630 & 52.0 & 59.0 & 7.0 & 9.0 & 15.5 \\
\hline 12 & 34.5 & 49.5 & 542 & 630 & 54.0 & 59.0 & 9.0 & 9.0 & 20.0 \\
\hline 13 & 36.5 & 49.5 & 574 & 630 & 56.0 & 56.0 & 11.0 & 6.0 & 24.4 \\
\hline 14 & 36.9 & 49.5 & 580 & 630 & 55.0 & 57.0 & 10.0 & 7.0 & 22.0 \\
\hline 15 & 35.0 & 49.5 & 550 & 630 & 55.0 & 58.0 & 10.0 & 8.0 & 22.0 \\
\hline
\end{tabular}

Note: $\mathbf{a}=$ Steel Non-Recognizable Origin $\mathbf{b}=$ Steel of Recognizable Origin 
Table 4: Results of the Tensile Test for the Computation of Characteristic Tensile Strength

\begin{tabular}{|c|c|c|c|c|c|c|c|c|c|c|}
\hline \multirow[t]{2}{*}{$\mathbf{S} / \mathbf{N}$} & \multicolumn{2}{|c|}{$\begin{array}{l}\text { Maximum Load } \\
(\mathbf{k N})\end{array}$} & \multicolumn{2}{|c|}{$\begin{array}{l}\text { Tensile Strength } \\
\left(\mathrm{kN} / \mathbf{m m}^{2}\right)\end{array}$} & \multicolumn{2}{|c|}{$\begin{array}{l}\text { Final Length } \\
(\mathrm{mm})\end{array}$} & \multicolumn{2}{|c|}{$\begin{array}{l}\text { Total Elongation } \\
(\mathrm{mm})\end{array}$} & \multicolumn{2}{|c|}{$\%$ Elongation } \\
\hline & $\mathbf{a}$ & $\mathbf{b}$ & $\mathbf{a}$ & b & $\mathbf{a}$ & b & $\mathbf{a}$ & b & $\mathbf{a}$ & $\mathbf{b}$ \\
\hline 1 & 53.0 & 68.0 & 469 & 602 & 73.0 & 63.0 & 13.0 & 3.0 & 22.0 & 5.0 \\
\hline 2 & 53.0 & 76.0 & 469 & 673 & 72.0 & 66.0 & 12.0 & 6.0 & 22.0 & 10.0 \\
\hline 3 & 53.0 & 76.0 & 469 & 673 & 75.0 & 64.0 & 15.0 & 4.0 & 25.0 & 7.0 \\
\hline 4 & 54.0 & 74.0 & 478 & 655 & 70.0 & 63.0 & 10.0 & 3.0 & 17.0 & 5.0 \\
\hline 5 & 53.0 & 76.0 & 469 & 673 & 79.0 & 68.0 & 19.0 & 8.0 & 32.0 & 13.0 \\
\hline 6 & 53.0 & 71.5 & 469 & 633 & 84.0 & 70.0 & 24.0 & 10.0 & 40.0 & 17.0 \\
\hline 7 & 53.0 & 70.5 & 469 & 624 & 80.0 & 70.0 & 20.0 & 10.0 & 33.0 & 17.0 \\
\hline 8 & 53.5 & 71.0 & 473 & 628 & 74.0 & 66.0 & 14.0 & 6.0 & 23.0 & 10.0 \\
\hline 9 & 53.5 & 76.5 & 473 & 677 & 73.0 & 71.5 & 13.0 & 11.5 & 22.0 & 19.0 \\
\hline 10 & 53.5 & 76.5 & 473 & 677 & 73.0 & 66.0 & 13.0 & 6.0 & 22.0 & 10.0 \\
\hline 11 & 53.5 & 76.0 & 473 & 673 & 76.0 & 68.0 & 16.0 & 8.0 & 27.0 & 13.0 \\
\hline 12 & 53.0 & 75.0 & 469 & 664 & 72.0 & 69.0 & 12.0 & 9.0 & 20.0 & 15.0 \\
\hline 13 & 53.8 & 72.0 & 476 & 637 & 71.0 & 68.0 & 11.0 & 8.0 & 18.0 & 13.0 \\
\hline 14 & 53.0 & 75.0 & 469 & 664 & 75.0 & 67.0 & 15.0 & 7.0 & 25.0 & 12.0 \\
\hline 15 & 54.0 & 75.0 & 478 & 664 & 75.0 & 66.0 & 15.0 & 6.0 & 25.0 & 10.0 \\
\hline
\end{tabular}

Note: $\mathbf{a}=$ Steel Non-Recognizable Origin $\quad \mathbf{b}=$ Steel of Recognizable Origin 
Table 5: Results of the Tensile Test for the Computation of Characteristics Tensile Strength and Mean Percentage Elongation for Steel of Bar Diameter 16mm

\begin{tabular}{|c|c|c|c|c|c|c|c|c|c|c|}
\hline \multirow[t]{2}{*}{$\mathbf{S} / \mathbf{N}$} & \multicolumn{2}{|c|}{$\begin{array}{l}\text { Maximum Load } \\
(\mathrm{kN})\end{array}$} & \multicolumn{2}{|c|}{$\begin{array}{l}\text { Tensile Strength } \\
\left(\mathrm{kN} / \mathrm{mm}^{2}\right)\end{array}$} & \multicolumn{2}{|c|}{$\begin{array}{l}\text { Final Length } \\
(\mathbf{m m})\end{array}$} & \multicolumn{2}{|c|}{$\begin{array}{l}\text { Total Elongation } \\
(\mathbf{m m})\end{array}$} & \multicolumn{2}{|c|}{$\%$ Elongation } \\
\hline & $\mathbf{a}$ & b & $\mathbf{a}$ & b & $\mathbf{a}$ & b & $\mathbf{a}$ & b & $\mathbf{a}$ & b \\
\hline 1 & 109 & 137 & 616 & 682 & 88.0 & 84.0 & 13.0 & 4.0 & 17.0 & 5.0 \\
\hline 2 & 98 & 133 & 554 & 662 & 100.0 & 95.0 & 25.0 & 15.0 & 33.0 & 19.0 \\
\hline 3 & 100 & 114 & 565 & 567 & 101.0 & 112.0 & 26.0 & 32.0 & 25.0 & 40.0 \\
\hline 4 & 99 & 132 & 559 & 657 & 86.0 & 117.0 & 11.0 & 37.0 & 15.0 & 46.0 \\
\hline 5 & 99.5 & 138 & 562 & 687 & 87.0 & 84.0 & 12.0 & 4.0 & 16.0 & 5.0 \\
\hline 6 & 97 & 126 & 548 & 627 & 84.0 & 95.0 & 9.0 & 15.0 & 1.0 & 19.0 \\
\hline 7 & 96 & 136 & 542 & 677 & 103.0 & 93.0 & 28.0 & 13.0 & 37.0 & 16.0 \\
\hline 8 & 92 & 133 & 520 & 662 & 93.0 & 93.0 & 18.0 & 13.0 & 24.0 & 16.0 \\
\hline 9 & 102 & 120 & 576 & 597 & 88.0 & 84.0 & 13.0 & 4.0 & 17.0 & 5.0 \\
\hline 10 & 98 & 132 & 554 & 657 & 95.0 & 95.0 & 20.0 & 15.0 & 27.0 & 19.0 \\
\hline 11 & 97 & 130 & 548 & 647 & 92.0 & 87.0 & 17.0 & 7.0 & 23.0 & 9.0 \\
\hline 12 & 98 & 133 & 554 & 662 & 92.0 & 96.0 & 17.0 & 16.0 & 23.0 & 20.0 \\
\hline 13 & 101 & 130 & 571 & 647 & 92.0 & 97.0 & 17.0 & 17.0 & 23.0 & 21.0 \\
\hline 14 & 109 & 137 & 616 & 682 & 88.0 & 85.0 & 13.0 & 5.0 & 17.0 & 6.0 \\
\hline 15 & 99 & 132 & 559 & 657 & 99.5 & 92.0 & 24.5 & 12.0 & 33.0 & 15.0 \\
\hline
\end{tabular}

Note: $\mathbf{a}=$ Steel Non-Recognizable Origin $\quad \mathbf{b}=$ Steel of Recognizable Origin 
Table 6: Results of the Tensile Test for the Computation of Characteristic Tensile Strength and Mean Percentage Elongation for Steel of Bar Diameter 20mm

\begin{tabular}{|c|c|c|c|c|c|c|c|c|c|c|}
\hline \multirow[t]{2}{*}{$\mathbf{S} / \mathbf{N}$} & \multicolumn{2}{|c|}{$\begin{array}{l}\text { Maximum Load } \\
(\mathrm{kN})\end{array}$} & \multicolumn{2}{|c|}{$\begin{array}{l}\text { Tensile Strength } \\
\left(\mathrm{kN} / \mathrm{mm}^{2}\right)\end{array}$} & \multicolumn{2}{|c|}{ Final Length (mm) } & \multicolumn{2}{|c|}{$\begin{array}{l}\text { Total Elongation } \\
(\mathrm{mm})\end{array}$} & \multicolumn{2}{|c|}{$\%$ Elongation } \\
\hline & $\mathbf{a}$ & b & $\mathbf{a}$ & b & $\mathbf{a}$ & b & $\mathbf{a}$ & $\mathbf{b}$ & $\mathbf{a}$ & $\mathbf{b}$ \\
\hline 1 & 156 & 219 & 497 & 697 & 119.0 & 117.0 & 19.0 & 17.0 & 19.0 & 17.0 \\
\hline 2 & 162 & 215 & 570 & 685 & 116.0 & 124.0 & 21.0 & 24.0 & 22.0 & 24.0 \\
\hline 3 & 146 & 212 & 465 & 675 & 126.0 & 111.0 & 26.0 & 11.0 & 26.0 & 11.0 \\
\hline 4 & 170 & 209 & 541 & 666 & 116.0 & 124.0 & 16.0 & 24.0 & 16.0 & 24.0 \\
\hline 5 & 148 & 228 & 521 & 726 & 116.0 & 115.0 & 21.0 & 15.0 & 22.0 & 15.0 \\
\hline 6 & 144 & 214 & 507 & 681 & 117.0 & 120.0 & 22.0 & 20.0 & 23.0 & 20.0 \\
\hline 7 & 154 & 215 & 490 & 685 & 121.0 & 124.0 & 21.0 & 24.0 & 21.0 & 24.0 \\
\hline 8 & 162 & 212 & 516 & 675 & 114.0 & 116.0 & 14.0 & 16.0 & 14.0 & 16.0 \\
\hline 9 & 158 & 197 & 556 & 627 & 116.0 & 108.0 & 21.0 & 8.0 & 22.0 & 8.0 \\
\hline 10 & 158 & 225 & 556 & 717 & 117.0 & 126.0 & 22.0 & 26.0 & 23.0 & 26.0 \\
\hline 11 & 156 & 221 & 549 & 704 & 117.0 & 121.0 & 22.0 & 21.0 & 23.0 & 21.0 \\
\hline 12 & 161 & 215 & 557 & 685 & 118.0 & 125.0 & 23.0 & 25.0 & 24.0 & 25.0 \\
\hline 13 & 165 & 218 & 525 & 694 & 114.0 & 122.0 & 14.0 & 22.0 & 14.0 & 22.0 \\
\hline 14 & 153 & 206 & 539 & 656 & 122.0 & 109.0 & 27.0 & 9.0 & 28.0 & 9.0 \\
\hline 15 & 167 & 223 & 532 & 710 & 125.0 & 121.0 & 25.0 & 21.0 & 25.0 & 21.0 \\
\hline
\end{tabular}

Note: $\mathbf{a}=$ Steel Non-Recognizable Origin

$\mathbf{b}=$ Steel of Recognizable Origin 
Table 7: Results of the Tensile Test for the Computation of Characteristic Tensile Strength and Mean Percentage Elongation for Steel of Bar Diameter 25mm

\begin{tabular}{|c|c|c|c|c|c|c|c|c|c|c|}
\hline \multirow[t]{2}{*}{$\mathrm{S} / \mathrm{N}$} & \multicolumn{2}{|c|}{$\begin{array}{l}\text { Maximum Load } \\
(\mathrm{kN})\end{array}$} & \multicolumn{2}{|c|}{$\begin{array}{l}\text { Tensile Strength } \\
\left(\mathrm{kN} / \mathrm{mm}^{2}\right)\end{array}$} & \multicolumn{2}{|c|}{$\begin{array}{l}\text { Final Length } \\
(\mathrm{mm})\end{array}$} & \multicolumn{2}{|c|}{$\begin{array}{l}\text { Total } \\
\text { Elongation } \\
(\mathrm{mm})\end{array}$} & \multicolumn{2}{|c|}{$\begin{array}{c}\% \\
\text { Elongation }\end{array}$} \\
\hline & $\mathrm{a}$ & $\mathrm{b}$ & $\mathrm{a}$ & $\mathrm{b}$ & $\mathrm{a}$ & $\mathrm{b}$ & $\mathrm{a}$ & $\mathrm{b}$ & $\mathrm{a}$ & $\mathrm{b}$ \\
\hline 1 & 215 & 314 & 475 & 639.5 & 165.0 & 159.5 & 45.0 & 34.5 & 37.5 & 28.0 \\
\hline 2 & 231 & 338 & 510 & 688 & 154.0 & 143.0 & 34.0 & 18.0 & 28.0 & 14.0 \\
\hline 3 & 216 & 335 & 477 & 682 & 153.0 & 154.0 & 33.0 & 29.0 & 27.5 & 23.0 \\
\hline 4 & 230 & 355 & 508 & 723 & 155.0 & 154.0 & 35.0 & 29.0 & 29.0 & 23.0 \\
\hline 5 & 231 & 307 & 510 & 625 & 146.0 & 158.0 & 26.0 & 33.0 & 2.0 & 26.0 \\
\hline 6 & 233 & 314 & 514 & 639.5 & 159.0 & 150.0 & 39.0 & 25.0 & 32.5 & 20.0 \\
\hline 7 & 235 & 328 & 519 & 668 & 160.0 & 155.0 & 40.0 & 30.0 & 33.0 & 24.0 \\
\hline 8 & 235 & 318 & 519 & 648 & 152.0 & 148.0 & 32.0 & 23.0 & 27.0 & 18.0 \\
\hline 9 & 233 & 305 & 514 & 621 & 148.0 & 155.0 & 28.0 & 30.0 & 23.0 & 25.0 \\
\hline 10 & 221 & 333 & 488 & 678 & 148.0 & 142.0 & 28.0 & 17.0 & 23.0 & 14.0 \\
\hline 11 & 229 & 338 & 505 & 688 & 145.0 & 147.0 & 25.0 & 22.0 & 21.0 & 18.0 \\
\hline 12 & 235 & 337 & 519 & 686 & 155.0 & 139.0 & 35.0 & 14.0 & 29.0 & 11.0 \\
\hline 13 & 232 & 338 & 512 & 688 & 164.0 & 149.0 & 44.0 & 24.0 & 37.0 & 19.0 \\
\hline 14 & 233 & 330 & 514 & 672 & 172.0 & 148.0 & 52.0 & 23.0 & 43.0 & 18.0 \\
\hline 15 & 229 & 351 & 505 & 715 & 153.0 & 154.0 & 33.0 & 29.0 & 27.5 & 23.0 \\
\hline
\end{tabular}

Note: $\mathbf{a}=$ Steel Non-Recognizable Origin 